\title{
Presence of Varicose Veins is the Most Important Risk Factor for Developing PTS
}

\author{
Hugo Partsch ${ }^{1}$ \\ ${ }^{1}$ Emeritus Professor of Dermatology, Medical University of Vienna, \\ Austria
}

Thromb Haemost 2018;118:1130.

Using complex statistical methods to establish a prediction model for post-thrombotic syndrome (PTS) after acute deep vein thrombosis (DVT), Amin et al in this issue of Thrombosis \& Haemostasis come up with a list of clinical risk scores, among which the presence of varicose veins received the highest score values, both for the first period (up to 6 months) and for the second phase 6 months after diagnosis. ${ }^{1}$ Additional risk factors such as age $>56$ or a body mass index $>30$ can further increase the risk of developing PTS to a total score of $>50 \%$. Surprisingly, iliofemoral DVT was found to have a much lower risk value concerning the development of a PTS for the first 6 months only.

Since varicose veins are a frequent condition and are easy to diagnose, these findings especially deserve clinical attention. In a recent case-control study, it had already been demonstrated that patients with DVT were 4.7 times more likely to have pre-existent primary valvular reflux than symptomatic controls, which then could contribute to more post-thrombotic morbidity. ${ }^{2}$

One of the main problems in using the Villalta score for defining PTS is its poor specificity. Pathological values may be seen in patients with varicose veins resulting in leg oedema and skin changes ('chronic venous insufficiency') without any evidence of previous episodes of DVT, which may lead to an over-diagnosis of PTS. Ideally, such patients should be excluded from follow-up trials concentrating on potential late sequelae regarding a PTS. ${ }^{3}$ Notably, the Villalta score is also elevated in the acute stage of DVT. For example, in the
Address for correspondence Hugo Partsch, Prof. Dr., Steinhäusl 126, Zwackgassse, 3033 Altlengbach, Austria (e-mail: Hugo.Partsch@meduniwien.ac.at).

SOX trial including only cases with a first episode DVT, the mean Villalta score was $>8 .^{4}$

However, one practical consequence from the Dutch study aiming to provide therapy to those patients who will likely benefit the most, would be to accordingly treat varicose veins as the most prominent risk factor of PTS. At least, in those patients with DVT who also show varicose veins (or signs of venous insufficiency) wearing of compression stockings should be considered as a basic recommendation. Future studies will be needed to evaluate a potential positive role of active interventions on varicose veins after DVT.

Conflict of Interest

None.

\section{References}

1 Amin EE, van Kuijk SMJ, Joore MA, Prandoni P, ten Cate H, ten CateHoek AJ. Development and Validation of a Practical Two-Step Prediction Model and Clinical Risk Score for Post-Thrombotic Syndrome. Thromb Haemost 2018;118(07):1242-1249

2 Shaydakov ME, Comerota AJ, Lurie F. Primary venous insufficiency increases risk of deep vein thrombosis. J Vasc Surg Venous Lymphat Disord 2016;4(02):161-166

3 Hach-Wunderle V, Bauersachs R, Gerlach HE, et al. Post-thrombotic syndrome 3 years after deep venous thrombosis in the Thrombosis and Pulmonary Embolism in Out-Patients (TULIPA) PLUS Registry. J Vasc Surg Venous Lymphat Disord 2013;1(01):5-12

4 Kahn SR, Shapiro S, Wells PS, et al, for the SOX trial investigators. Compression stockings to prevent post-thrombotic syndrome: a randomized placebo-controlled trial. Lancet 2014;383(9920): 880-888 received

May 9, 2018

accepted

May 9, 2018 (c) 2018 Georg Thieme Verlag KG Stuttgart · New York
DOI https://doi.org/ 10.1055/s-0038-1660859. ISSN 0340-6245. 